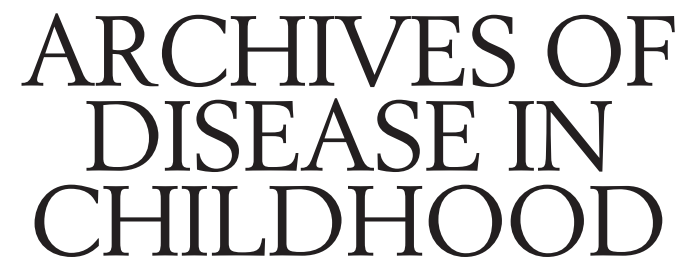

The Fournal of the Royal College of Paediatrics and Child Health

\title{
Multiple causes of human kidney malformations
}

\section{Anatomy of human nephrogenesis}

The human kidney derives from two parts of the metanephros, its embryonic precursor. The first of these is the ureteric bud, which branches into the collecting ducts containing $\mathrm{K}^{+}$secreting principal and $\mathrm{H}^{+}$handling intercalated epithelia, and also forms the urothelium of the calyces, renal pelvis, ureter, and bladder trigone. The second is the renal mesenchyme, which differentiates into nephrons comprised of glomeruli, proximal tubules, and loops of Henle. The human metanephros appears at 5 weeks of gestation, the first glomeruli form by 9 weeks, and nephrogenesis is complete by 34 weeks. $^{12}$

\section{Variety of human kidney malformations}

The term 'renal malformation' encompasses a mixed bag of developmental aberrations, all of which involve anatomical or major structural anomalies which are present at the time of birth. ${ }^{12}$ In the most extreme example, called renal agenesis, the kidney is absent. Renal dysplasia describes an organ comprised of undifferentiated and metaplastic cells: these organs may be tiny (renal aplasia) or can distend the abdomen (the multicystic dysplastic kidney). A hypoplastic kidney is small and has fewer nephrons than normal: these nephrons may be grossly enlarged in oligomeganephronia.

This classification is ultimately based on histopathology, yet in clinical practice it is unusual to have the luxury of viewing renal biopsy material from these children. The diagnoses on discharge summaries are often best guesses based on a detailed review of the clinical history combined with radiological appearances.

Table 1 Multiple causes of human renal malformations

Teratogens

Dietary agents, for example vitamin A

Metabolites, for example glucose

Drugs, for example angiotensin enzyme converting inhibitors

Obstruction of fetal urinary tract

Anatomical obstruction, for example urethral valves

Physiological obstruction, for example neurogenic bladder

Primary genetic defects

Transcription factors, for example $P A X 2$ mutation in renal-coloboma syndrome

Growth factor signalling, for example FGFR2 mutation in Apert's syndrome

Cell adhesion molecules, for example $K A L$ mutation in X linked Kallmann's syndrome

Miscellaneous, for example mutation of peroxisomal protein in Zellweger syndrome
Other familiar malformations include the ectopic, duplex, and horseshoe kidney and these organs may include both dysplastic and normal tissues. Associated malformations of the urinary tract include agenesis, duplications, and obstruction of the upper (for example hydronephrosis) or lower (for example posterior urethral valves) tract, as well as vesicoureteric reflux. Human renal malformations are the major causes of end stage renal failure in children less than 5 years of age. ${ }^{3}$ As the techniques of dialysis and transplantation continue to be refined, there are increasing numbers of infants with renal malformations entering programmes for the treatment of renal failure.

Some of the varieties of polycystic kidney disease may present at birth. These disorders include autosomal recessive polycystic kidneys and the disorder resulting from contiguous deletion of the TSC2 (tuberous sclerosis 2) and PKD1 (an autosomal dominant polycystic kidney disease) genes. These entities are, however, best considered as disorders of terminal epithelial differentiation and the gross structural steps of nephrogenesis (for example nephron formation and collecting duct morphogenesis) are complete. Therefore they will not discussed further in this paper, although details can be found elsewhere. ${ }^{4-7}$

\section{Renal malformation as a dynamic process}

This classification of renal malformations is a rather dry system based on pathological end points. Yet we now know, based on a wealth of animal experiments, that normal kidney development is a highly dynamic and tightly controlled programme of cellular events comprising: (a) cell proliferation; (b) cell death by apoptosis (about $50 \%$ of cells formed in the developing kidney are destined to die before birth); (c) morphogenesis or the acquisition of three dimensional form (for example the formation of a nephron tubule from undifferentiated cells or the branching of the collecting ducts); and (d) differentiation into specific cell types including diverse epithelia, mesangial cells, and endothelia. ${ }^{7}$

These processes are controlled and mediated by the temporal and spatial expression in the developing kidney of genes coding for molecules which generally fall into a few classes: (a) transcription factors which orchestrate the expression of other genes; (b) growth factors which act in paracrine or autocrine fashion; (c) survival factors which prevent apoptosis; and (d) adhesion molecules which hold cells to one another or anchor them to adjacent matrices. ${ }^{8-10}$ 
It is interesting to observe the multicystic dysplastic kidney with these perspectives in mind. Serial ultrasound scans performed prenatally and postnatally have shown that some of these organs can increase to a massive size, then subsequently regress and even involute completely. ${ }^{11}$ Detailed examination of these organs shows that epithelial cells lining the cysts resemble undifferentiated ureteric bud branches and have a high rate of proliferation which is correlated with the expression of PAX2, a potentially oncogenic transcription factor, and BCL2, a survival molecule. ${ }^{12}{ }^{13}$ Preliminary evidence, based on gene expression patterns, also suggests that soluble paracine signalling molecules, such as hepatocyte growth factor and insulinlike growth factor II, may drive the expansion of these cysts. ${ }^{14}{ }^{15}$ Conversely, tissue around these cysts has a high rate of apoptosis, or programmed cell death, which is associated with a lack of BCL2 and PAX2 expression and a failure to differentiate into functioning nephrons. ${ }^{13} 16$

Hence we can begin to correlate phases of growth and involution with cellular events and the aberrant expression of master nephrogenesis genes. Furthermore, an understanding of the dynamics which underlie these malformations now allows us to envisage potential treatments, especially the administration of growth factors which prevent apoptosis and enhance normal differentiation into nephrons. The deregulated expression of these genes, although intriguing, is likely to be a secondary event and the question remains: what are the primary causes of human kidney malformation? From first principles, I suggest that there will be three answers (table 1): teratogens, physical obstruction of the urinary tract, and sporadic or inherited mutations of genes expressed in the developing kidney.

\section{Teratogens}

A wide variety of agents has been implicated as renal teratogens based on animal studies ${ }^{17}$ and one of the best studied is vitamin $\mathrm{A}$. When administered to mice in large doses just before the formation of the metanephros, this vitamin causes massive apoptosis in the renal mesenchyme followed by the involution of the organ to cause renal agenesis. ${ }^{18}$ Other experiments suggest that ethanol is teratogenic for the urinary tract later in gestation and this substance also induces premature cell death. ${ }^{19}$ In humans, both glucose (that is, a mother with diabetes) and angiotensin converting enzyme inhibitors (that is, drugs used for maternal hypertension and now contraindicated) are recognised renal teratogens. ${ }^{17}{ }^{20}$ It is unusual to elicit a history of exposure to known teratogens from the parents of children with renal malformations, but it remains possible that 'occult' exposure is important. For example, one study has suggested that the incidence of various

Table 2 Examples of human renal malformations associated with genetic defects

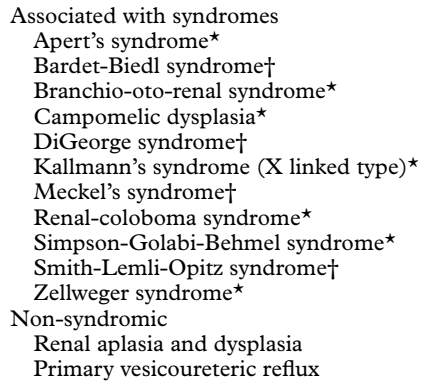

$\star$ Defined mutation.

† Locus known, but gene not yet known.

For the exact types of renal malformation in each disorder, please refer to references 2,7 , and 42 .

\section{Key messages}

- The next decade will see further progress in defining genetic causes of human renal malformations; in cases where the mutation is inherited this may lead to prenatal diagnosis very early in gestation

- Appreciation of the biology of malformed kidneys is beginning to suggest therapeutic options to alter aberrant developmental processes

- The possibility that low grade exposure to tetatogens can cause renal malformations requires further investigation, but may have major health implications

malformations, including those of the kidney, was increased with a daily intake vitamin A over levels as low as $10000 \mathrm{IU}^{21}$

\section{Physical obstruction of the urinary tract}

It has long been recognised that a significant minority of kidney malformations in girls, and perhaps half of all malformations in boys, are associated with physically obstructed lower urinary tracts at the level of the pelviureteric junction, ureter, or urethra. ${ }^{122}$ Obstruction in the last third of gestation is associated with hydronephrosis, poor renal parenchymal growth, and subcortical cysts. Kidneys associated with obstruction in early gestation are usually dysplastic. Bilateral obstructive fetal nephropathy causes oligohydramnios with lung hypoplasia and severely affected infants die after birth from respiratory or renal failure. Although prenatal surgical decompression is technically feasible, there are few controlled clinical studies assessing the potential beneficial effects on lung and kidney development.

Preliminary data suggest that the experimental obstruction of murine kidneys in the neonatal period causes enhanced cell death by apoptosis, as well as aberrant patterns of expression the BCL2 survival factor, transforming growth factor $\beta 1$, angiotensin II, and epidermal growth factor. $^{23}$ All these molecules have been functionally implicated in metanephric growth in various other experiments using organ culture or transgenic mice. It will be interesting to see whether these same molecules can be implicated in the pathogenesis of renal dysplasia, a phenotype which can be generated in animals, such as sheep, by ureteric obstruction much earlier during development. ${ }^{24}$

\section{Mutations}

Mutations of genes expressed in nephrogenesis can occur spontaneously in mice or be created by the genetic engineering of early murine embryos; an increasing number of genes (currently about 10) has been found to be essential for normal nephrogenesis. ${ }^{7-10}$ Important lessons with considerable implications for human disease include the fact that a single mutation can cause a range of renal malformations, with particular phenotypes appearing to depend on the mouse strain (that is genetic background), hence suggesting the presence of modifying genes. ${ }^{25} \mathrm{We}$ also know that in certain cases the deficiency of a particular gene can be compensated for by the expression of another molecule with similar functions. ${ }^{26} 27$ The same phenotype (for example agenesis, dysplasia) can result from the mutation of very different genes, perhaps indicating that the developing kidney has a limited number of ways of reacting to 'molecular lesions'. In the same way, diverse primary insults to the adult kidney tend to lead to a final common pathway of glomerular and interstitial 
fibrosis. Finally, mouse models have shown that nephrogenesis genes are usually expressed in other organs where they are sometimes critical for normal development.

The same genes which have been implicated in mouse nephrogenesis are likely to be important in human development, an excellent example being the $P A X 2$ transcription factor gene. ${ }^{28}$ The ablation of a single $P A X 2$ allele in mice causes impaired metanephric growth and fewer nephrons than normal as well as megaureter, a finding consistent with gross vesicoureteric reflux. These animals are also blind, due to maldevelopment of the retina, another site of embryonic PAX2 expression. There is a human syndrome which is strikingly similar to these mouse models, namely the renal-coloboma syndrome. This comprises blindness due to optic nerve colobomas, and renal failure and hypertension associated with vesicoureteric reflux and small, malformed kidneys. This resemblance was noted by a New Zealand based laboratory where workers described heterozygous mutations of $P A X 2$ in patients with this syndrome. ${ }^{29}$ These mutations most likely result in haploinsufficiency (that is a partial lack of functional protein) and they can arise de novo or be inherited in an autosomal dominant manner. Various research groups are now searching for mutations of genes such as $P A X 2$ in non-syndromic cases of human vesicoureteric reflux; this common disorder is often inherited in a dominant manner. ${ }^{30} 31 \mathrm{PAX} 2$, or a similar gene, might also be implicated in the rare families reported with inherited non-syndromic kidney aplasia and dysplasia. ${ }^{32}$

Congenital malformation syndromes are individually often rare, but collectively account for considerable morbidity and even mortality in young children. Many affect the kidney in a way which can be mild or which can dominate the clinical course. Some clearly have a genetic basis and loci have been defined. For example, renal malformations occur in Bardet-Biedl syndrome (loci at $11 \mathrm{q}$, $3 p, 16 q$, and 15q), Meckel's syndrome (17q), and DiGeorge syndrome (22q). In addition, specific mutations in some of these syndromes have been clarified (table 2): the eyes absent gene, a putative transcription factor expressed in renal mesenchyme in branchio-oto-renal syndrome $^{33}$; SOX 9 , a transcription factor expressed in embryonic collecting ducts in campomelic dysplasia ${ }^{34}$; $F G F R 2$, a receptor for fibroblast growth factor receptor 2 in Apert syndrome ${ }^{35}$; GPC3, a gene encoding an extracellular proteoglycan in Simpson-Golabi-Behmel syndrome ${ }^{36}$; $K A L$, a gene encoding another cell signalling molecule in $\mathrm{X}$ lined Kallmann's syndrome ${ }^{37}$; mutation of a peroxisome assembly gene in Zellweger syndrome ${ }^{38}$; mutation of a cholesterol biosynthesis gene in Smith-Lemli-Opitz syndrome $^{39} ; F A A$, a gene implicated in DNA repair in a variety of Fanconi's anaemia ${ }^{40}$; and $W T 1$, a transcription factor gene mutated in Denys-Drash syndrome. ${ }^{41}$ There are over 100 varieties of inherited syndromes with kidney malformations, so there is plenty of scope for further research in this field! ${ }^{42}$

\section{Nephrourology Unit,}

ADRIAN S WOOLF

\section{Institute of Child Health,}

University College Hospital Medical School,

London WC1E 1EH

Correspondence to: Nephrourology Unit, Institute of Child Health, 30 Guilford Street, London WC1E 1EH.

1 Potter EL. Normal and abnormal development of the kidney. Chicago: Year Book Medical Publishers, 1972

2 Bernstein J, Risdon RA, Gilbert-Barness E. Renal system. In: GilbertBarness E, ed. Potter's pathology of the fetus and infant. St Louis: Mosby, 1996: 863-922

3 Ehrich JHH, Rizzoni G, Brunner FP, et al. Renal replacement therapy for end-stage renal failure before 2 years of age. Nephrol Dial Transplant 1992; 7:1171-7.
4 Zerres K, Mucher G, Bachner L, et al. Mapping of the gene for autosomal recessive polycystic kidney disease (ARPKD) to chromosome $6 \mathrm{p} 21$-cen. Nature Genet 1994;7:429-32.

5 Brook-Carter PT, Peral B, et al. Deletion of the TSC2 and PKD1 genes associated with severe infantile polycystic kidney disease-a contiguous gene syndrome. Nature Genet 1994;8:328-32.

6 Feather S, Woolf AS, Malcolm S, Donnai D, Winter R. The oral-facialdigital syndrome type 1 (OFD1), a cause of polycystic kidney disease and associated malformations, maps to Xp22.2-22.3. Hum Molec Genet 1997;7: 1163-7.

7 Woolf AS. The biology of kidney malformations. In: Thorogood P, ed. Embryos, genes and birth defects. Chichester: Wiley, 1997:303-27.

8 Rothenpieler UW. Roles of Pax genes in nephrogenesis. Exp Nephrol 1996;4: $86-91$

9 Woolf AS, Cale CM. Roles of growth factors in renal development. Curr Opin Nephrol Hypertens 1997;6:10-4.

10 Ekblom P. Extracellular matrix and cell adhesion molecules in nephrogenesis. Exp Nephrol 1996;4:92-6.

11 Mesrobian H-GJ, Rushton HG, Bulas D. Unilateral renal agenesis may result from in utero regression of multicystic dysplasia. 7 Urol 1993;150:793-4.

12 Winyard PJD, Risdon RA, Sams VR, Dressler GR, Woolf AS. The PAX2 transcription factor is expressed in cystic and hyperproliferative dysplastic epithelia in human kidney malformations. F Clin Invest 1996;98:451-9.

13 Winyard PJD, Bao Q, Hughes RC, Woolf AS. Epithelial galectin-3 during human nephrogenesis and childhood cystic diseases. $7 \mathrm{Am}$ Soc Nephrol (in press)

14 Kolatsi-Joannou M, Moore R, Winyard PJD, Woolf AS. Expression of $\mathrm{HGF} / \mathrm{SF}$ and its receptor, MET, suggests roles in human embryonic organogenesis. Pediatr Res 1997;41:657-65.

15 Matsell DG, Bennett T, Armstrong RA, Goodyer P, Goodyer C, Han VKM. IGF and IGF binding protein gene expression in multicystic renal dysplasia. F Am Soc Nephrol 1997;8:85-94.

16 Winyard PJD, Nauta J, Lirenman DS, et al. Deregulation of cell survival in cystic and dysplastic renal development. Kidney Int 1996;49:135-46.

17 Brown NA: Chemical teratogens: hazards, tools and clues. In: Thorogood P, ed. Embryos, genes and birth defects. Chichester: Wiley, 1997:69-88.

18 Tse HKW, Woolf AS, Gosling JA, Shum ASW. Embryonic development of renal agenesis in a mouse model (poster presentation). Proceedings of British renal agenesis in a mouse model (poster presentation). Proc
Society for Developmental Biology. Spring 1997; Warwick.

19 Gage JC, Sulik KK. Pathogenesis of ethanol-induced hydronephrosis and hydroureter as demonstrated following in vivo exposure of mouse embryos. hydroureter as demonstrated
Teratology. 1991;44:299-312.

20 Novak RW, Robinson HB. Coincident Di George anomaly and renal agenesis and its relation to maternal diabetes. Am f Med Genet 1994;50:311-2

1 Rothman KJ, Moore LL, Singer MR, Nguyen U-SDT, Mannino S, Milunsky A. Teratogenicity of high vitamin A intake. $N$ Engl $f \mathrm{Med}$ 1995;333:1369-73

22 Thorner P, Bernstein J, Landing BH. Kidney and lower urinary tract. In: Reed GB, Claireaux AE, Cockburn F, eds. Diseases of the fetus and newborn. 2nd Ed. London: Chapman and Hall Medical, 1995:609-91.

23 Chevalier RL. Growth factors and apoptosis in neonatal ureteral obstruction. F Am Soc Nephrol 1996;7:1098-105.

24 Beck $\mathrm{AD}$. The effect of intrauterine urinary obstruction upon the development of the fetal kidney. $f$ Urol $1971 ; 105: 784-9$.

25 Threadgill DW, Dlugosz AA, Hansen LA, et al. Targeted disruption of mouse EGF receptor. Effect of genetic background on mutant phenotype. Science 1995;269:230-4

26 Mendelsohn C, Lohnes D, Decimo D, et al. Function of the retinoic acid receptors (RAR) during development. Development 1994;120:2749-71.

27 Davis AP, Witte DP, Hsieh-Li HM, Potter SS, Capecchi MR. Absence of radius and ulna in mice lacking hoxa-11 and hoxd-11. Nature 1995;375: 791-5.

28 Favor J, Sandulache R, Neuhauser-Klaus A, et al. The mouse Pax $2^{1 \text { Neu }}$ mutation is identical to a human PAX2 mutation in a family with renal-coloboma syndrome and results in developmental defects of the brain, ear, eye and kidney. Proc Natl Acad Sci USA 1996;93:13870-5.

29 Sanyanusin P, Schimmentl LA, McNoe LA, et al. Mutations of the PAX2 gene in a family with optic nerve colobomas, renal anomalies and vesicoureteral reflux. Nature Genet 1995;9:358-64.

30 Feather S, Gordon I, Risdon RA, Woolf AS, Verrier-Jones K. Vesicoureteric reflux - is it all in the genes? Lancet 1996;348:725-8.

31 Feather SA, Woolf AS, Blaydon D, Allison J, Barratt TM, Malcolm S. Exclusion of key nephrogenesis genes as candidates for familial, primary, non-syndromic vesicoureteric reflux. 7 Am Soc Nephrol 1997;8:388A.

32 McPherson E, Carey J, Kramer A, et al. Dominantly inherited renal adysplasia. Am f Med Genet 1987;26:863-72.

33 Abdelhak S, Kalatzis V, Heilig R, et al. A human homologue of the drosoplila eyes absent gene underlies branchio-oto-renal (BOR) syndrome and identifies a novel gene family. Nature Genet 1997;15:157-64.

34 Wagner T, Wirth J, Meyer J, et al. Autosomal sex reversal and campomelic dysplasia are caused by mutations in and around the SRY-related gene SOX9. Cell 1994;79:1111-20.

35 Wilkie AOM, Slaney SF, Oldridge M, et al. Apert syndrome results from localised mutations of FGFR2 and is allelic with Crouzon syndrome. Nature Genet 1996;9:165-72.

36 Pilia G, Hughes-Benzie RM, MacKenzie A, et al. Mutations in GPC3, a glypican gene, cause the Simpson-Golabi-Behmel overgrowth syndrome. Nature Genet 1996;12:241-7.

37 Duke V, Winyard PJD, Thorogood PV, Soothill P, Bouloux PMG, Woolf AS. KAL, a gene mutated in Kallmann's syndrome, is expressed in the first trimester of human development. Mol Cell Endocrinol 1995;110:73-9.

38 Shimozawa N, Tsukamoto T, Suzuki Y, et al. A human gene responsible for Zellweger syndrome that affects peroxisome assembly. Science 1992;255: 1132-4.

39 Irons M, Elias ER, Salen G, Tint GS, Bastta AK. Defective cholesterol biosynthesis associated with the Smith-Lemli-Opitz syndrome. Lancet 1993;341:1414.

40 Lo Ten Foe JR, Rooimans MA, Bosnoyan-Collins L, et al. Expression cloning for the major Fanconi anaemia gene, FAA. Nature Genet 1996;14:320-3.

41 Coppes MJ, Huff V, Pelletier J. Denys-Drash syndrome: relating a clinical disorder to alterations in the tumor suppressor gene WT1. F Pediatr 1993; 123:673-8.

42 McKusick VA. Mendelian inheritance in man. 10th Ed. Baltimore: Johns Hopkins University Press, 1992. 


\section{Can measures of infant habituation predict later intellectual ability?}

By the end of the 1970s, about 50 years of research had shown fairly clearly that prediction coefficients from measures of infant behaviour to later measures of intelligence in childhood were so low as to indicate that, except in extreme cases such as severe subnormality, the early measures had no predictive validity. ${ }^{12}$ From about this time, however, researchers began to question the nature and validity of the infant tests on which these findings were based. It was argued that the 'mental scales' on these tests primarily measured perceptual and motor development, rather than mental or cognitive growth, and there is little reason to expect measures of such abilities to predict later IQ. ${ }^{3}$

Accordingly, the search began for cognitive or information processing measures of infant performance which might more reasonably be considered to tap abilities that are similar to, and may be predictive of, the abilities measured by the childhood intelligence tests. A major focus of this research has been on measures of visual information processing and attentiveness, and it has become clear that a moderate degree of predictability may be possible, leading some to the view that the 'promise of greater predictive accuracy using recognition memory and habituation rate represents one of the most exciting contemporary fields of inquiry' ${ }^{5}$

\section{Problems with standardised infant tests}

One of the best known and most widely used tests of infant development is the Bayley scales of infant development (BSID). In the second edition of these scales published in 1993, many items on the mental development index appear to measure perceptual-motor rather than mental or cognitive development. At 4 months the items include: \#36 'eyes follow rod'; \#44 'uses eye-hand coordination in reaching'; and \#45 'picks up cube'. At 12 months the items include: \#73 'turns pages of book'; \#79 'fingers holes in pegboard'; and \#97 'builds tower of three cubes'. By 2 years of age such seemingly perceptual-motor items are fewer in number and they have been replaced with a preponderance of items that would generally be considered more mental or 'cognitive': verbal comprehension, recall of geometric forms, and comparison of masses. From about 2 years of age the predictive validity of the BSID increases. ${ }^{26}$ Similar comments apply to other well known tests of infant development, such as the Griffiths' scales. ${ }^{7}$

Several studies have introduced programmes in which infants at risk of intellectual retardation have been given educational intervention designed to enhance their cognitive development. At the end of the first year these groups did not seem to differ from non-intervention control groups. ${ }^{8}$ A likely interpretation of these findings is that the mental scales used to evaluate the effectiveness of these programmes were simply not measuring mental or cognitive growth and there is therefore a great need for a valid test of infant cognitive development.

\section{Visual information processing}

Control of attention, memory formation, and the ability to process information quickly and efficiently have traditionally been conceived of as being central to mature cognitive functioning. ${ }^{10}{ }^{11}$ In the search for predictors of later intelligence a major focus has been on measures of visual information processing and attentiveness as these appear to be measuring these abilities: 'attentiveness reflects not only the detection of information but also the ongoing processing of that information and the status of the relation between the new information and the child's existing knowledge'. ${ }^{12}$ Measures of habituation to visual stimuli in particular have been seen as potential predictors of later intelligence.

Habituation is an aspect of learning in which repeated presentations of a stimulus result in decreased responsiveness. When an infant is placed in an otherwise homogeneous environment and shown a visual stimulus the stimulus will initially attract the infant's attention, but as time passes the infant's attention will wane (as measured by reduced looking). Habituation refers to this decrement in visual attention and measures of this decrement reflect memory formation (of the now familiar stimulus), and therefore the processing of information from the stimulus, and may also be an indication of infants' ability to inhibit attention to the familiar stimulus. ${ }^{13}$

For several other reasons measures of habituation have been seen as potential predictors of later intellectual functioning: (a) there are interage differences in speed of habituation, with older infants taking less time to reach a criterion of habituation than younger infants, ${ }^{14}$ and there are also intra-age differences; (b) infants who habituate in shorter times have been found to process information more rapidly and more efficiently than 'long lookers' ${ }^{15}$; and (c) infants 'at risk' for cognitive delay or handicap habituate less effectively than non-risk infants matched for age. ${ }^{16-18}$

\section{Psychometric considerations}

There are many different habituation procedures and many different dependent measures that can be drawn from them. ${ }^{19}$ An important enterprise is to establish the psychometric adequacy of these measures, particularly by examining their test-retest reliabilities. Those measures that give the best reliabilities are likely to be the best potential predictors because if a measure does not correlate with itself it is unlikely to correlate well with other concurrent or future measures.

Several groups of workers have assessed the short and long term reliability of various measures of habituation in the first year after birth ${ }^{20-22}$ and the results are both encouraging and discouraging. What is encouraging is that measurements at points close in time (separated by a few days or weeks) tend to give reliability estimates in the range $r=$ $0.40-0.60$, but what is discouraging is that measurements separated by a month or more tend to yield lower estimates, with $r$ values in the range $0-0.20$. Thus these infant measures tend to have low test-retest reliabilities and this will inevitably limit the maximum predictive correlations that might be found.

\section{Predictive validity of visual information processing} Three measures can be distinguished which have some predictive power: (a) visual recognition memory (preferences for a novel stimulus after a brief look at a 'familiarised' stimulus); (b) the time taken to reach a criterion of habituation and associated measures (such as the duration of the longest single or peak look); and (c) the duration of individual fixations to visual stimuli, independent of habituation. There are many studies that have reported predictive correlations and several reviews of these studies are available. ${ }^{31923}$ The measures predicted are 
usually the scores of the subjects on childhood intelligence tests, and the delay between testing as infants and testing as children can vary between months and several years. The predictive correlations that have been reported occasionally approach 0.6 , but are usually in the range $0.3-0.5$, with a median correlation of around $0.45 .^{23}$

\section{Failures to replicate and the 0.05 syndrome}

Lécuyer $^{24}$ refers to what he calls 'the 0.05 syndrome' and points out that 'It is difficult to publish an experimental paper if no statistical tests reach this magical level of significance. So, how many studies exist that show no correlation between infancy and childhood measures?' One failure to replicate was reported by Lewis and Brooks-Gunn, ${ }^{2}$ who found the rate of habituation in 3 month old infants to be predictive of the 2 year Bayley mental development index for one group of 22 infants $(r=$ 0.61 ), but for a second group the identical measure gave a non-significant negative correlation of -0.18 . In another study with 2263 month old 'at risk' infants, 11 measures of looking were extracted and few of these correlated either with the Bayley mental development index at 2 years or with several cognitive tests at 4.5 years. ${ }^{25}$

One finding that is relevant is that the size of the predictive correlations to be found in the literature is correlated with sample size $(r=0.6) .^{3}$ The most reasonable interpretation of this is that very high and very low correlations are likely to be found with smaller samples and the studies finding low, non-significant correlations are not likely to be published. What this means, unfortunately, is that the published predictive correlations are almost certainly a biased sample of the whole research enterprise and are almost certainly an overestimation of the 'real' predictive correlations. Data have been collected from 420 infants who, at 4 months old, completed a habituation task as part of the Avon longitudinal study on pregnancy and childhood and they have subsequently been tested on later measures of language acquisition and abilities, and at 4 years on the Wechsler preschool and primary scales of intelligence. This is the largest sample that, to date, has been tested on a habituation task and at the time of writing the ability of the habituation measures to predict the later outcome measures has not been assessed: these data will eventually give a clear indication of the usefulness of measures of habituation as predictors.

Predictors other than visual information processing Many studies have used measures other than those derived from visual information processing. These measures include differential vocal responsiveness to the mother and strangers, visual anticipation, the mother's encouraging attention, cross modal transfer, symbolic play, means-ends problem solving, perception of causal relations, and various measures of language development. ${ }^{11} 1926$ These studies are not reviewed here, but at present it seems reasonable to conclude that (with the exception of the language measures, which are inevitably taken in late infancy) at present none of them has been shown to have a greater predictive validity than measures of visual information processing.

\section{Theoretical implications}

Twenty years ago the poor long term predictive validity of infant tests led to theoretical views that emphasised the discontinuity of intellectual functioning from infancy to childhood: 'No science can predict accurately qualities which have not yet made any appearance in the development of the pre-school child'. ${ }^{27}$ Thus it was reasonable to argue that the types of intelligence we wanted to predict, and which would be important in the school years (language, numeracy, thinking, problem solving, and reasoning) developed in the post-infancy years and that measures of intelligence in infancy (if it existed) would not predict these later appearing abilities. ${ }^{28}$

The demonstrations of developmental continuity (however modest the predictive correlations) mean that we can probably reject such extreme models and suggests that it is reasonable to look for genuine precursors of childhood intellectual abilities in infancy. Predictive correlations of the magnitude reported, however, give ample scope for theorists who wish to emphasise discontinuity and open endedness, rather than continuity of development.

\section{Social and cultural influences on IQ}

However good our measures of infant function, they can only give an indication of mental growth or cognitive ability at the time of testing. Clearly, later IQ will be considerably modified by social factors ${ }^{19}$ and a valid test of infant cognitive abilities will be of inestimable value in allowing the quantification of the role of such factors in the early months after birth.

\section{Conclusions}

Measures of visual information processing taken in infancy have been shown to predict measures of intelligence in childhood. The predictive correlations are, however, modest (usually in the range 0.3-0.5) and correlations for identical or similar measures have a habit of fluctuating from one study to another. This is to be expected given the variations in sample characteristics and in the social and cultural factors that influence development, but it is a little more worrying when the correlations disappear altogether! What is certainly the case is that the prediction of an individual infant's current cognitive ability or future intellectual development is not yet possible. ${ }^{1129}$

Although it may be possible to use measures of visual information processing to make predictions for groups of infants, the search must continue for a greater number of reliable measures of infant cognitive performance before a useful test of infant mental or cognitive development can emerge.

Department of Psychology,

ALAN SLATER

Washington Singer Laboratories,

University of Exeter,

Exeter EX4 $4 Q G$

1 Bayley N. The Bayley scales of infant development. New York: Psychological Corporation, 1970

Lewis M, Brooks-Gunn J. Visual attention at three months as a predictor of cognitive function at two years of age. Intelligence 1981;5:131-40.

3 Bornstein MH, Sigman MD. Continuity in mental development from infancy. Child Dev 1986;57:251-74.

4 Slater A, Cooper R, Rose D, Morison V. Prediction of cognitive performance from infancy to early childhood. Hum Dev 1989;32:137-47.

5 McCall RB. Commentary. Hum Dev 1989;32:177-86.

6 Bayley N. Consistency and variability in the growth of intelligence from bayley $\mathrm{N}$. Consistency and variability in the growth of
birth to eighteen years. $\mathcal{F}$ Genet Psychol 1949;75:165-96.

7 Griftiths $\mathrm{B}$ The abilities of babies: Psychol 1949;75:165-96. McGraw-Hill, 1954.

8 Ramey CT, Yeates KO, Short EJ. The plasticity of intellectual development: Ramey CT, Yeates KO, Short EJ. The plasticity of intellectual develo
insights from preventive intervention. Child Dev 1984;55:1913-25.

9 Brooks-Gunn J, Klebanov PK, Liaw F-R, Spiker D. Enhancing the developBrooks-Gunn J, Klebanov PK, Liaw F-R, Spiker D. Enhancing the develop-
ment of low-birthweight premature infants: changes in cognition and behavior over the first three years. Child Dev 1993;64:736-53.

10 Bornstein $\mathrm{MH}$. Habituation of attention as a measure of visual information processing in human infants: summary, systematization, and synthesis. In: Gottleib G, Krasnegor NA, eds. Measurement of audition and vision in the first year of postnatal life: a methodological overview. Norwood: Ablex, 1985:253-300.

11 Bornstein MH, Slater A, Brown E, Roberts E, Barrett J. Stability of mental development from infancy to early childhood: three 'waves' of research. In: Bremner JG, Slater A, Butterworth G, eds. Infant development: recent advances. Hove: Psychology Press, 1997:191-215.

12 Reznick JS, Corley R, Robinson J. A longitudinal twin study of intelligence in the second year. Monographs of the Society for Research in Child in the second year. Meropment 1997;249:62.

$13 \mathrm{McCall}$ RB. What process mediates predictions of childhood IQ from infant habituation and recognition memory? Speculations on the roles of inhibition and rate of information processing. Intelligence 1994;18:107-25. 
14 Slater A, Morison V. Selective adaptation cannot account for early infant habituation: a response to Dannemiller and Banks. Merrill-Palmer Quarterly habituation: a resp

15 Colombo J, Mitchell DW, Coldren JT, Freesman LJ. Individual differences in infant visual attention: are short lookers faster processors or feature processors? Child Dev 1991;62:1247-57.

16 Cohen LB. Examination of habituation as a measure of aberrant infant development. In: Friedman SL, Sigman M, eds. Preterm birth and psychological development. New York: Academic Press, 1981:241-53.

17 Friedman S. Infant habituation: process, problems, and possibilities. In: Ellis $\mathrm{N}$, ed. Aberrant development in infancy: human and animal studies. New York: Halstead Press, 1975:217-39.

18 Lester BM. Cardiac habituation of the orienting response to an auditory signal in infants of varying nutritional status. Dev Psychol 1975;11:432-42. Slater A. Individual differences in infancy and later IQ. F Child Psychol Psychiatry 1995;36:69-112.

20 Colombo J, Mitchell DW, O'Brien M, Horowitz FD. The stability of visual habituation during the first year of life. Child Dev 1987;58:474-87.

1 Pêcheux MG, Lécuyer R. A longitudinal study of visual habituation between 3, 5 and 8 months of age. Br f Dev Psychol 1989;7:159-69.
22 Rose DH, Slater AM, Perry H. Prediction of childhood intelligence from habituation in early infancy. Intelligence 1986;10:251-63.

$23 \mathrm{McC}$ all RB, Carriger MS. A meta-analysis of infant habituation and recognition memory performance as predictors of later IQ. Child Dev 1993;64:57-79.

24 Lécuyer R. Habituation and attention, novelty and cognition: where is the continuity? Hum Dev 1989;32:148-57.

25 Laucht M, Esser G, Schmidt M. Contrasting infant predictors of later cognitive functioning. I Child Psychol Psychiatry 1994;35:649-62.

26 Dougherty TM, Haith MM. Infant expectations and reaction time as predictors of childhood speed of processing and IQ. Dev Psychol 1997;33: 146-55.

27 Clarke A. Predicting human development: problems, evidence, implications. Bull Br Psychol Soc 1978;31:249-58.

$28 \mathrm{McC}$ all RB. Qualitative transitions in behavioral development in the first two years of life. In: Bornstein $\mathrm{MH}$, Kessen W, eds Psychological development from infancy: image to intention. Hillsdale: Erlbaum Associates, 1979:183-224.

29 Cohen SE, Parmelee AH. Prediction of five-year Stanford-Binet scores in preterm infants. Child Dev 1983;54:1242-53.

\section{Treatment of oesophageal varices}

Bleeding from oesophageal varices is the most common cause of serious gastrointestinal haemorrhage in children. Bleeding may occur at any age, but some patients with varices never bleed. ${ }^{1}$ The risk of bleeding is not linearly related to portal pressure, but to the size of the varix and the thickness and integrity of its wall. ${ }^{2}$ Thus varices are most likely to bleed if they project prominently into the oesophageal lumen, if the overlying mucosa is blue, and particularly if there are 'cherry red spots' on the varix. Salicylate ingestion used to be recognised as an important precipitant.

The treatment of bleeding oesophageal varices is dependent on the underlying cause. In patients with portal hypertension from intrahepatic liver disease treatment is dictated by the latter and may determine the need for liver transplantation. Patients with good liver function and bleeding varices can, however, be successfully managed by treatment of their portal hypertension alone. Opinions on the primary management of extrahepatic portal hypertension have long been divided between those who advocate portosystemic shunting and those who favour endoscopic injection sclerotherapy. The results from studies of large series of children undergoing endoscopic injection sclerotherapy have encouraged the widespread acceptance of this technique in children with intrahepatic disease, in whom prognosis is determined more by underlying liver pathology, and in those with portal vein thrombosis or presinusoidal venous obstruction in whom variceal bleeding is the main threat to life..$^{3-5}$

The management of acute variceal bleeding involves prompt but careful resuscitation. Shock should be corrected by cautious blood transfusion, but over transfusion may increase splanchnic blood flow and precipitate rebleeding. Coagulopathy and severe thrombocytopenia (platelet count less than $50 \times 10^{9} / 1$ ) require correction and sepsis should be sought and treated with intravenous antibiotics. Patients must be monitored closely for continuing haemorrhage and the development of hepatic encephalopathy, and arrangements should be made for transfer to a centre where flexible fibreoptic endoscopy can be carried out by an operator skilled in injection sclerotherapy.

The use of somatostatin and its longer acting synthetic analogue octreotide has not been fully evaluated in children. In some adult studies these drugs have proved to be as effective as emergency sclerotherapy ${ }^{67}$ and balloon tamponade ${ }^{8}$ in controlling bleeding. Moreover, they are easily administered by continuous intravenous infusion and serious side effects are very rare. They may be particularly useful in stabilising a child before transfer or in preventing early rebleeding after sclerotherapy. ${ }^{9}$ As they are not effective in non-variceal gastrointestinal bleeding, ${ }^{10}$ diagnostic upper gastrointestinal endoscopy is essential.

Flexible fibreoptic endoscopy is ideally carried out under general anaesthesia with an endotracheal tube in situ within 24 hours of presentation. After assessment of the varices and the upper gastrointestinal tract, the varices are injected using a flexible endoscopic needle. Injections are concentrated at the cardia and in the lower $3 \mathrm{~cm}$ of the oesophagus (the site of perforating veins) and are predominantly intravariceal. The details of the technique and type of sclerosant have been reviewed elsewhere. ${ }^{11}$ Patients are given ranitidine and sucralfate by mouth for up to two weeks after each injection session and antibiotic prophylaxis is recommended for those with damaged/ prosthetic heart valves. The initial two or three treatments are performed at weekly intervals, but injection is deferred for one week if significant oesophageal mucosal ulceration is present. Further treatments are given at one to three monthly intervals until the varices have either disappeared or been converted into thrombosed cords. Most varices can be obliterated within one year by five to eight injection sessions. ${ }^{3}$ Regular checks, usually as a day case, are then carried out every six to 18 months until a stable state is achieved.

The efficacy of sclerotherapy in treating oesophageal varices is clearly shown by the King's College Hospital series of 108 children treated in the 1980 s. $^{3}$ Endoscopically confirmed obliteration of bleeding oesophageal varices was achieved in all children with portal vein obstruction and $84 \%$ of those with intrahepatic disease (for example, biliary atresia, congenital hepatic fibrosis, cystic fibrosis). All but one of the children whose varices were not obliterated did not complete a course of sclerotherapy because of liver transplantation or death from liver failure. Only one child died from variceal haemorrhage.

Injection sclerotherapy has been associated with numerous complications, ${ }^{11}$ but these are rarely serious in children. Transient fever and mild retrosternal discomfort are common sequelae after injection and are usually self limiting, but may signify bacteraemia. Gastrointestinal bleeding before variceal obliteration is complete occurs in $40 \%$ of patients ${ }^{3}$ and is usually due to a non-thrombosed varix or an oesophageal mucosal ulcer, but may be secondary to peptic ulceration. The short term incidence of recurrent oesophageal varices and bleeding from gastric varices is low $(<10 \%)$ and the former often respond to further sclerotherapy. ${ }^{3}$ In adults, sclerotherapy ulcers can be reduced by prophylactic ranitidine ${ }^{12}$ and the incidence of oesophageal strictures can be decreased by using smaller 
volumes of sclerosant and prophylactic sucralfate. ${ }^{13}$ Some children develop oesophageal dysmotility and gastrooesophageal reflux, which may cause intermittent dysphagia and heartburn. Systemic dissemination of the injected sclerosant leading to distant complications has been reported, but appears to be rare..$^{114}$

Little is known about the long term outcome of children after injection sclerotherapy for bleeding oesophageal varices. In those with cirrhosis, the long term outcome is jeopardised not only by the complications of portal hypertension, but also by deteriorating liver function. Treatment of bleeding oesophageal varices by sclerotherapy is effective in controlling haemorrhage and, unlike portosystemic shunting, does not reduce portal perfusion or carry the risk of encephalopathy. Moreover, it does not add to the technical difficulties of liver transplantation provided sclerotherapy is not carried out immediately before surgery. Those with serious underlying liver disease are, however, often best managed by liver transplantation. For children with extrahepatic portal hypertension, indications for surgery include uncontrollable variceal bleeding, bleeding from gastric or ectopic varices not accessible to sclerotherapy, lack of access to expert sclerotherapy, and severe symptomatic hypersplenism. ${ }^{15}$ In one study of 32 children with portal vein thrombosis followed up for a mean period of nine years after endoscopic variceal obliteration, recurrent variceal bleeding developed in 10 (31\%) patients, but half of these were effectively controlled by further sclerotherapy. ${ }^{14}$ Gastric variceal bleeding not amenable to sclerotherapy necessitated portosystemic shunt surgery in four $(13 \%)$ patients. Two patients required a splenectomy for symptomatic hypersplenism. Endoscopic injection sclerotherapy alone was safe and effective in controlling variceal bleeding from portal hypertension in the long term in over $80 \%$ of children with portal vein occlusion.

Two new treatments have affected the management of bleeding oesophageal varices, but their precise role in children has yet to be determined. The first is variceal band ligation, which has been adopted by many as the preferred method of endoscopic control of bleeding oesophageal varices in adults with cirrhosis. It achieves variceal obliteration more quickly, with a lower rebleeding rate than injection sclerotherapy, and complications such as oesophageal stricture may be reduced. ${ }^{16}{ }^{17}$ It is no more effective than sclerotherapy in controlling active haemorrhage, however, and recurrent varices may be more common. Preliminary clinical experience in children ${ }^{18}{ }^{19}$ suggests that the technique is possible in those older than 2 years, but it is currently more cumbersome than sclerotherapy.

The transjugular intrahepatic portosystemic stent shunt is the second novel approach, whereby a stent is inserted between the portal and hepatic veins within the liver. This can be useful as a temporary measure in selected patients with complicated portal hypertension who are waiting for liver transplantation, but long term patency rates are unknown and reports to date simply suggest that it is a feasible option in some children. ${ }^{20}$

The role of $\beta$ blockers in children with portal hypertension remains uncertain. These drugs reduce portal venous inflow by decreasing cardiac output and by blocking $\beta$ receptors in the splanchnic vascular bed. In adults, trials with propranolol in patients who have already bled from varices have yielded mixed results and if there is a benefit, it is likely to be modest. ${ }^{21}$ Uncontrolled studies in children do no more than point to a possible role. ${ }^{22}$ Although $\beta$ blockers may be of value in primary or secondary prophylaxis, there is no good evidence to support prophylactic injection sclerotherapy. ${ }^{11}$

Department of Paediatric Surgery, Clarendon Wing,

MARK D STRINGER

Leeds General Infirmary, Belmont Grove,

Leeds LS2 9NS

St fames's University Hospital,

PATRICIA MCCLEAN

Beckett Street,

Leeds LS9 7 TF

1 Bernard O, Alvarez F, Brunelle F, Hadchouel P, Alagille D. Portal hypertension in children. Clin Gastroenterol 1985;14:33-55.

2 Dawson JL Oesophageal varices: curiosities. BMF 1983;286:826.

3 Howard ER, Stringer MD, Mowat AP. Assessment of injection sclerotherapy in the management of 152 children with oesophageal varices. $\mathrm{Br} F$ Surg 1988;75:404-8.

4 Maksoud JG, Goncalves MEP, Porta G, Miura I, Velhote MCP. The endoscopic and surgical management of portal hypertension in children: analysis of 123 cases. $\mathcal{F}$ Pediatr Surg 1991;26:178-81.

5 Paquet KJ, Lazar A. Current therapeutic strategy in bleeding esophageal varices in babies and children and long-term results of endoscopic paravariceal sclerotherapy over twenty years. Eur f Pediatr Surg 1994;4:16572 .

6 Shields R, Jenkins SA, Baxter JN, et al. A prospective randomised controlled trial comparing the efficacy of somatostatin with injection sclerotherapy in the control of bleeding oesophageal varices. F Hepatol 1992;16:128-37.

7 Sung JJY, Chung SCS, Lai CW, Chan FKL, Leung JWC, Yung MY. Octreotide infusion or emergency sclerotherapy for variceal haemorrhage. Lancet 1993;342:637-41.

8 Avgerinos A, Kionis C, Rekoumis G, Gaima P, Papadimitriou N, Raptis S. A prospective randomised trial comparing somatostatin, balloon tamponade and the combination of both methods in
variceal haemorrhage. $\mathcal{F}$ Hepatol 1991;13:78-83.

9 Bessan I, Ingraud P, Person B, et al. Sclerotherapy with or without octreotide Bessan I, Ingraud P, Person B, et al. Sclerotherapy with or with
for acute variceal bleeding. $N$ Engl f Med 1995;333:555-60.

10 Christiansen J, Ottenjann R, Von Arx F. Placebo-controlled trial with the somatostatin analogue SMS 201-995 in peptic ulcer bleeding. Gastroenterology 1989;97:568-74.

11 Stringer MD, Howard ER. The role of endoscopic injection sclerotherapy in the management of portal hypertension in children. In: Howard ER, ed. Surgery of liver disease in children. Oxford: Butterworth-Heinemann, 1991:157-70.

12 Kumar A, Mehta SR, Joshi V, Kasthuri AS, Narayanan VA. Ranitidine for the prevention of complications following endoscopic sclerotherapy for esophageal varices. $\mathcal{F}$ Assoc Physicians India 1993;41:584-9.

13 Guady H, Rosman A, Korssen M. Prevention of stricture formation after endoscopic sclerotherapy of esophageal varices. Gastrointest Endosc 1989;35:377-80

14 Stringer MD, Howard ER. Long term outcome after injection sclerotherapy for oesophageal varices in children with extrahepatic portal hypertension. for oesophageal varices

15 Heaton ND, Howard ER. Complications and limitations of injection sclerotherapy in portal hypertension. Gut 1993;34:7-10

16 Gimson AES, Ramage JK, Panos MZ, et al. Randomised trial of variceal banding ligation versus injection sclerotherapy for bleeding oesophageal varices. Lancet 1993;342:391-4.

17 Laine L, Cook D. Endoscopic ligation compared with sclerotherapy for treatment of esophageal variceal bleeding. A meta-analysis. Ann Intern Med 1995;123:280-7.

18 Cano I, Urruzuno P, Medina E, et al. Treatment of esophageal varices by endoscopic ligation in children. Eur f Pediatr Surg 1995;5:299-302.

19 Fox VL, Carr-Locke DL, Connors PJ, Leichtner AM. Endoscopic ligation of esophageal varices in children. F Pediatr Gastroenterol Nutr 1995;20:2028.

20 Schweizer P, Brambs HJ, Schweizer M, Astfalk W. TIPS: a new therapy for esophageal variceal bleeding caused by EHBA. Eur 7 Pediatr Surg 1995;5:211-5.

21 Vickers C, Rhodes J, Chesner I, et al. Prevention of rebleeding from oesophageal varices: two-year follow-up of a prospective controlled trial of propranolol in addition to sclerotherapy. $f$ Hepatol 1994;21:81-7.

22 Shashidhar H, Pizzi AM, Grand RJ, Langhans NA. Use of propranolol in prevention of portal hypertensive haemorrhage in children. Gastroenterology 1996;110:A838. 